\title{
Improving the Performance and Satisfaction of Students in Embedded Systems with PBL Approach
}

\author{
Harshad N. Lokhande \\ Department of Electronics and Telecommunication Engineering \\ NBN Sinhgad School of Engineering \\ Pune, India \\ email: lokhande.harshad@gmail.com \\ Shriram D. Markande \\ Department of Electronics and Telecommunication Engineering \\ NBN Sinhgad School of Engineering \\ Pune, India \\ email: sdmarkande@hotmail.com
}

Abstract - In the under graduate studies, teaching the concepts in the course on Embedded Systems has been always challenge for the faculty. Performance of many students is not up to mark as well as the joy of learning is also not observed in them. This paper is based on the experiments carried out with Project Based Learning (PBL) approach with Rubric's reviews. The study developed a method of self-learning to apply core electronics knowledge to increase student performance and keen interest in Microcontrollers and its applications. The new design method consists of eight-week PBL strategy to work in group of three students to solve real-world problems. The student's quality results were improved by $8 \%$ and overall performance in scaled up by $29 \%$ as compared to successive previous two years. Also, the feedback from the students shows satisfaction as well as joy of learning.

Keywords- Project Based Learning, PBL approach, Microcontrollers, Problem solving, Rubric

\section{INTRODUCTION}

$\mathrm{T}$ HIS engineering education comes under modern sciences, especially when compared to physics, mathematics or Medical Sciences. But the traditional learning methods like "Chalk and talk", prunes more towards the mathematical and physical background [1]. According to current industry demands engineers must need to apply their knowledge in real time situations. Considering electronics and telecommunication engineering students they're going to cope with IT sectors as well As in Core electronics industries. So, the hands-on experience and practical mechanism must student have to understand with core electronics concepts as well as the higher technologies which are the key arts in engineering education system. Hence instead of belonging only on traditional teaching and learning engineering mechanism it's time to enhance the students' knowledge with a new mechanism like project-based learning, flipped classrooms and online digital learning [2]. When adopting PBL in classroom student will get benefits like the core application of interdisciplinary skills planning teamwork and a different learning tools which will help to motivate the students to get ready for industrial needs. When The educational system from first year covers the basic knowledge of the subject and gradually student will get attracted towards the subject specific interest like mobile communication, embedded systems, VLSI, image processing or deep learning and artificial intelligence [3].

\section{BACKGROUND}

Those students have learned basic skills of electronics, they must have to apply and check the knowledge from the subject. Thus, instead of just believing on theoretical knowledge it's time to apply it practically on engineering project and check the students' knowledge thoroughly [4]. The study shows that only 4.77 per cent candidates could write the perfect logical programs which is an essential for any engineer must to do [9].

In this paper we analyze and evaluate the results of PBL mechanism with typical embedded systems subject "microcontroller and its applications". A group of students, evaluated with embedded systems knowledge and practically 
implementation skills from design to product development stages. The main teaching skills acknowledged with this methodology's are:

- It will help to keep students busy with real time practical problems to solve some issues, challenges from social background or community needs.

- $\quad$ Student will also learn to work as a team with selfregulated atmosphere. The students will understand to unify themselves by dividing the work between the skill sets that they acquired. with excellent teamwork they will understand the assistances of good project planning and the usage of advance tools like different embedded systems software and the implementation skills of hardware [5].

- The core electronics knowledge can help to create high quality solutions to the given problem. the students are facing the problems with new innovative solutions and design methodologies to implement in their solution.

This will help to enhance their creative sets and the proactiveness to help them become a proficient in industrial demands and requirements [6].

- To achieve this motive, a complete team of expertise will be guiding them throughout the project. an individual attention will be provided to each student to solve the problem. according to the students level a customized knowledge sharing will be giving a better result in project-based learning [7].

\section{A. Related Work}

In current scenario once student is entered in engineering, he is spending his almost 3 years to understand the core branch. In final year he is getting chance to apply competencies for major project with all his electronics skills. But due to lack of confidence and a fear in mind to lose marks into the final exam, most of the student's intention is to work on the project in isolation basis. According to the report published by [8], $80 \%$ students of engineering are unemployable due to lack of practical skills which is biggest tragedy in engineering domain specially when we are talking about electronics and telecommunication sector. So, there is a gap between the actual engineering methods to learn and to apply in general practice. The teachers are giving satisfactory and high-quality education to the students but there are many reasons by which the students are diverted from their goal [11]. some of the reasons are:

- They have fear in their mind that if I don't work then I might be getting fail in the exam.

- Students are not coming regularly to attend the practical, hence they are diverting from the actual understanding of hardware knowledge and model implementation.

The 3rd but the most important students are having fear in their mind about the subject understanding hence they are very less interested in the particular subjects like microcontrollers or embedded systems.

Being of such issues how to apply the core electronics knowledge to work on the subject is challenge. This can be solved at some level with project-based learning as discussed in this paper.

The project-based learning is helpful in microcontrollers subject to improve the result of the students in quantitative as well as the qualitative manner. The final results after applying PBL method are compared with previous 2 years results to map the improvement in students progress. Beside the core PBL, other features like student survey, the parents survey and the faculty service are considered to enhance the project-based learning mechanism [9]. The PBL is structured with Rubric's marking scheme. The benchmarking of the students has been linked with the campus placement offered to the students.

\section{B. Challenge in Understanding Embedded Systems}

In early engineering stages, students acquire knowledge from digital electronics with core understanding of Boolean logic, digital logic gates and mux circuits. In Microcontrollers subject, 8-bit to 32-bit controllers are explored with hardware interfacing to software implementation. This subject is difficult to understand, as the working of ALU, CPU with types of architectures varies between Harvard and VonNeumann [13]. The special peripherals interact with outer world physical quantities with Timers, PWM and communication protocols like UART, SPI and I2C. Hence even students are learning this subject with 3 types of CPU's as 8051-8-bit Von-Neumann, Atmega 328-8-bit as Harvard and ARM7 - 32-bit as Harvard, still they are not finding themselves as confident to handle these controllers at individual level.

While working on final year project, students are facing lot of complications and difficulties in hardware. Even from component identification to PCB implementation, most of the students are just seating idle throughout project work. Students are getting scope to work for complete two semesters, but even they have time, due to competitive exams, campus drives and social events hardly involved into complete project development phase.

They are completing the allotted project tasks, but as group, they are not well versatile with all essential skills. The scope of project is uncategorized, hence complete tasks handling is unsynchronized.

\section{INTENDED OUTCOMES}

Before starting Microcontrollers contents as described here, candidate should familiar with basic courses for understanding fundamentals of electronics, digital circuits, analog electronics, and software programming languages. The procedure used in those paths comprised of problem solving, lectures with laboratory practical work on syllabus mapped Student Evaluation Kits. In parallel to Microcontrollers, students also finish few labs on ' $\mathrm{C}$ ' language, in which they learn to develop the logic understanding and boost problem solving skills. Under the University scaled, value addition programs student must have to complete, the skillsets to design the printed circuit board (PCB) for the deploying Microcontrollers and interfacing stuff. The Embedded Systems taught as two modules as beginner level on 8-bit and expert 
level on 32-bit microcontrollers. The current project aims on 8-bit systems as having of the teacher explaining theoretical aspects with problem solving skills in class, later students work with pre-defined development boards and evaluation programs in laboratory slots. But, still these well-established structures of education may at perform unsatisfactory level.

Considering above facts, the projected outcomes for the new learning method PBL planned to:

1) To increase passing ratio of students [10].

2) Students can work in regular flow during the semester, moderately forcing them before the exam. This result will straight help in achieving the prior outcome.

3) Students will take high interest in the field of embedded systems design.

\section{METHODOLOGY}

To enhance the students learning graph, Project Based Learning procedure was applied with the Arduino based microcontroller interfacing on different sensors, general purpose input output (GPIO) devices the laboratory sessions.

PBL reports the first two outcomes. Further this method is compared with following.

1) Chalk and Talk teaching in theory and practical sessions, with In-semesters and oral exams. Some advancement

could be expected, but to limited extend.

2) Internal Marks Assessments. Each subject includes a termwork on the topic, which is assessed and mapped for the final grades. Although this is a decent technique for finding the basic few outcomes, PBL proposes better results with students gaining extra opportunities to apply practical skills in scoring achievement [12].

The third outcome was highlighted by social problems in advanced level applications including GSM, GPS or WiFi TABLE I

SCHEDULE OF PBL

\begin{tabular}{|c|c|}
\hline Week No. & SCOPE \\
\hline $1^{\text {st }}-2^{\text {nd }}$ & \begin{tabular}{c} 
study the Microcontroller basics, \\
sensors and protocols + Review 1 \\
Define Problem Statement for PBL \\
\hline $3^{\text {rd }}$
\end{tabular} \\
\hline $4^{\text {th }}$ & $\begin{array}{c}\text { interfacing diagram and making of } \\
\text { PCB design }\end{array}$ \\
\hline $5^{\text {th }}$ & $\begin{array}{c}\text { Review 2 and PCB Implementation \& } \\
\text { Design Issues }\end{array}$ \\
\hline $6^{\text {th }}$ & Embedded C - Programming \\
\hline $7^{\text {th }}$ & Review 3 with working module \\
\hline $8^{\text {th }}$ & Final report and project execution \\
\hline $9^{\text {th }}$ & Project Presentation and Evaluation \\
\hline
\end{tabular}

based protocols.

It is observed that students work more reliably under PBL rather than under a normal examination pattern, investing more time on the subject and accomplishing improved academic grades [14].

\section{A. Workflow}

Because they had a enough workload at the end of the semester, and due to submissions, mock exams, practical journals they could get enough time for examinations and the final throughputs. This challenge can be solved with the new practices known as PBL.

The scope of work under PBL is programmed for eight weeks (as shown in Table II). In prior two weeks, students study the Microcontroller basics, working principles, Timers, Communication Protocols and Embedded C language briefs, making study documents that includes block diagrams, sample GPIO examples and few assembly programs to understand the CPU Architecture.

In third week, student has to identify the key aspects from problem definition and has to prepare the synopsis on topic. In fourth week, hardware design, basic interfacing diagram and making of PCB design should be covered with simple PCB design software. PCB artwork design using an appropriate EDA tool, Simulation is mandatory.

\section{B. Review mechanism}

In the fifth week, the prior checking of circuit diagram and related modification are proposed to group from expert panels. Then they will start to build final approved PCB and components installations.

Students work in groups on the finalizing design and in sixth week the software implementation of project has to start. The complete coding will be in embedded $C$ language with modular programming in Sketch or relevant Software. In last two weeks, the linking of software with hardware has been targeted for sensor interfacing and reading input devices. With accomplishing the final demonstrations, there are transitional milestones and questionnaires that detect student's continuous performance by their actively involvement in their group.

PBL specialists assumes that old-style teaching produces slightly better results in academic knowledge and in solving typical problems, but PBL harvests meaningfully improved results in overall skills leverages much better academic outcomes. The valuation is based on State-of-the-art methodologies, scope of understanding, Applications in realtime, Individual level contributions, presentation, and the grade given by the internal expert guide based on the work carried out during 8 weeks.

\section{Scope of PBL Project}

\section{1) Context:}

The Microcontrollers and Applications course is taught in the fifth semester of the third year of the engineering degree program in electronics and telecommunication engineering. The course contents include 8051 microcontrollers, its architecture details and peripheral interfacing. It is expected to apply these learned skills under Employability Skills and Mini Project course in sixth semester. The course has 60 class hours ( $48 \mathrm{~h}$ in class and $12 \mathrm{~h}$ in the laboratory), so students are expected to engage for $70 \mathrm{~h}$ outside class in private study and working with their groups. The PBL projects mentioned in Table III 
are mapped for $70 \mathrm{~h}$, divided into 30 class hours and $40 \mathrm{~h}$ of personal and group work. All projects will be carried out in groups of three.

\section{2) Project:}

The defined projects GSM Based Home Security Alarm System Using Arduino and Home automation using Alexa and Node-MCU are explored here. In 1st project, sensors are aligned to detect an intruder person inside the premises. If person has detected, an ultrasonic sensor will give input to microcontroller. By setting safe distance between two points, the home is kept under observation. If intruder is detected, GSM will send an SMS via communicating on serial com protocol. Thus, an alert will be triggered to house owner and also to police station to avoid the theft. This is one way to have security to home. But if you have advanced internet communication, then 2nd project is developed under Amazon's Alexa Personnel Smart Assistance. If sensor is triggered the instead of sending a traditional SMS, the node-MCU is linked to cloud for making systems as an IoT enabled.

\section{3) Deliverables:}

Each group must undergo two design reviews and one final review

I. First Review: In first review, student has to identify the project topic and the scope of work. Based on literature survey, the prior findings of project observed for focusing on main objectives of PBL. A group of three students giving presentation with synopsis on project.

II. Second and Third Review: Once objectives are defined; second review brings more clarity in the sensors and PCB designing. The projects are judged by the teacher and by student hands-on evaluation for final grades in final review.

\section{4) Assessment:}

Each group must undergo two design reviews and one final review

I. Subject understanding and problem-solving capability $(25 \%)$. If group failed in this review, then new project will be assigned to student as second chance. Thus, based on scope and understanding, students will be getting good marks.

II. The implementation of Product Development Process $(65 \%)$.

III. Document Design and report writing (10\%).

5) Supportive Learning in the Project:

I. True Growth in Individual Skills: With involvement in project at individual level, every student's grades raised if overall the group's members get best results in theory.

II. The Experts View: Each student differs with knowledge base in subject, hence overall ranking will be calculated by teachers based on presentation skills.

III. Personnel Interview and Presentations: Students are working separately on modules, but unitedly they have to give presentations. Project Groups are learning simultaneously on curriculum subjects and on PBL. So, oral questions and professional skills are scaled with interviews and review presentations.

IV. Group Commitment and Leadership: Between 8 weeks, groups perform a project development activity with mini project and PBL based rules. The expert teacher evaluates this in subparts and brings feedback. Some coaching is provided on project management skills and team leadership. The teacher searches for best leader and that member is selected for final extra grades.

V. Group Processing: Involving them in group with progress report in group activities. Each students task has been observed in logbooks. Each student must have to learn to take self-decisions for making this project successful in collaboration with other students.

\section{GSM Based Home Security Alarm System Using Arduino}

\section{1) Design Task:}

This project based on home security with GSM module, with controlling the home appliances, using the simple GSM mobile, only by sending SMS through his phone. Even without internet and Smart phone, just the old mobile phone with simple GSM capabilities will work to switch "ON" and "OFF" any home electronic appliances, from anywhere. With Ultrasonic sensor, an intruder will be detected and alert will be conveyed to owner.

\section{2) Sensory System:}

It consists of several sensors like Ultrasonic or IR sensors for detecting persons presence for opening or closing the doors. LPG gas sensor helps to detect smoke and gas leakage in house to alert about presence of fire. Such sensing values are sent to the Arduino in the form of Analog value in scale 0 to $5.5 \mathrm{VDC}$. The ADC of Arduino Uno with Atmega 328 is 10 bit, hence the ADC resolution will be $4.88 \mathrm{mV} /$ digital count.

If voltage at sensor is $3.5 \mathrm{~V}$, then, Arduino shows digital output calculated using equ. (1) as:

Digital Output $=\frac{\text { Analog Voltage } \mathrm{I} / \mathrm{P}}{\text { Vref } / 1024}$

$$
=3.5 V D C \times \frac{5 V D C}{1024}
$$

$$
=3500 \mathrm{mV} \times \frac{5000 \mathrm{mV}}{1024}
$$

$$
=717.21 \approx 717 \text { in digital }
$$

$$
=717.21
$$

So, if analog sensor is giving input voltage $3.5 \mathrm{~V}$, then digitally its 717 in count. 


\section{3) GSM Modem:}

GSM module permits to send and receive messages, to call the number using microcontroller-based devices. It consists of a Standard SIM card and operates over a mobile frequency $800 \mathrm{Mhz}$ or $900 \mathrm{Mhz}$. It is a very friendly to handle like without any device drivers this device is capable of connecting to a Desktop Computer or any 8051 or Arduino like microcontroller's serial port through Max232 IC [13]. This Max232 IC is used to converts the TTL logic levels of the microcontroller $(3.3 \mathrm{~V})$ to a RS232 logic level for establishing serial communication between different devices having multiple operating voltage levels.

\section{4) Design Data for GSM Based Project:}

I. PCB Mounting: Once the design is finalized, and components are fixed. Next task is to develop the PCB using circuit diagram as mentioned below. There are many choices for PCB software, but open source platforms are chosen for final implementation [12]. The circuit diagram is shown in figure 1 .

II. List of Components

$\begin{array}{ll}\text { - } & \text { Arduino UNO } \\ \text { - } & \text { GSM Module } \\ \text { - } & \text { Ultrasonic Sensor } \\ \text { - } & \text { Smoke Detector Sensor } \\ \text { - } & \text { ULN2003 } \\ \text { - } & 5 \text { V Relays } \\ \text { - } & \text { NodeMCU } \\ \text { - } & \text { Power supply }\end{array}$

III. Working Principle: The various devices like sensors, ADC, relays and keypad are connected to Arduino. In this system, an LCD interfaced with 4-bit communication via normal GPIO's of the Arduino. ADC to the analog pin 2 and a matrix keypad to the I2C port. To provide extra security, may smoke detector is connected to analog pin 4; a temperature measurement sensor LM35 and a Light Dependent Resistor (LDR) are connected to the channel pin 7 and 8 of the ADC, respectively.

All analog sensor values are sent to the ADC where these are then converted to digital understandable and controlling logic. Based on true situations the decisions are taken.

If person triggers as intruder, or if smoke sensor detects fault in gas then immediate signal will be passed to GSM modem as serial data as AT-Commands like "ATDxxxx" or "AT+CMGS" to call the owner or to alert the user by SMS.

\section{E. GSM Based Home Security Alarm System Using Arduino}

Second project given to few groups have shown improved results in reliability, accuracy and multiple ways to alert with enhanced home security. The complete project scaled with internet and its benefits to provide more convenience to home owner. Once Arduino is on internet with Node-MCU as modem, the alert data from user is immediately transmitted to owner.

\section{FINDINGS}

1) Increased Students Passing Ratio

Instead of depending on just practical session during curriculum, students had shown consistency in doing PBL based projects. The total number of students appeared for University examination in Year 2018-19 are 70. Out of 7 failed and 63 were passed.

In Year 2019-20, 42 students appeared for University exam, out of 39 were passed with good marks and 3 failed. The overall results of students from Year 209-20 were improved in both quantitative and qualitative measures.

I. Quantitative Performance: The graph in fig. 2 is showing comparison between last two years passing

\section{Quantitative Performance of Students in Examination (\%)}
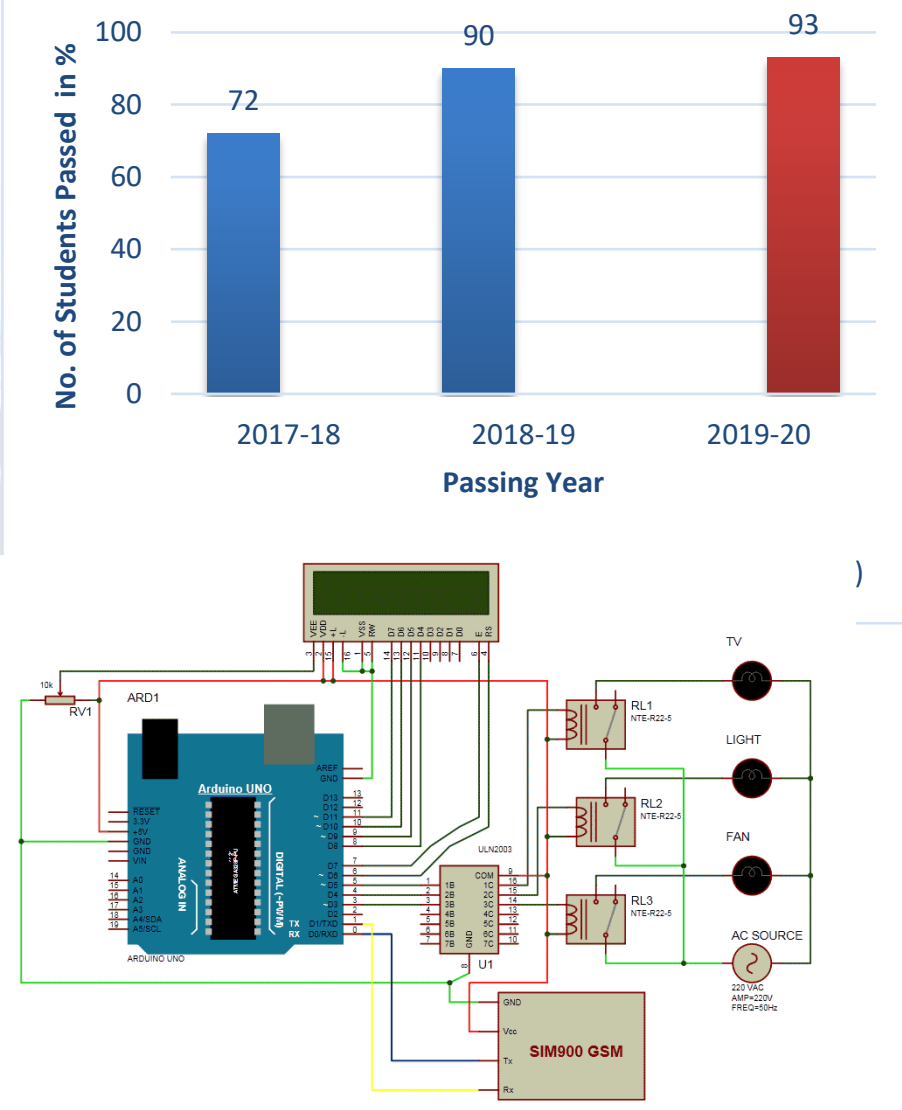

Fig. 1. Interfacing of Arduino with Ultrasonic sensor, GSM Module, NodeMCU and other peripherals

ratio of students under University Exams in Microcontrollers course (without PBL) and with PBL in quantitative way. It is observed that, students passing ratio has been increased by $3 \%$ after implementing PBL on class of year 2019-20. 
TABLE II

Highlighting Qualitative PeRformance PoInTs with PBL

Remarks on University Examination Results with PBL

- The average number of passing students in range of above 60 marks is improved by $8 \%$ in distinction class.

- $\quad$ The average of passing students in range of marks between $51-60$ in improved by $13 \%$ in first class.

- The average number of passing students below second class is reduced by $7.61 \%$.

- $\quad$ The overall result has been improved with $29 \%$

Fig. 2. The graph is showing comparative quantitative performance between last two years (without PBL) and with PBL students passing ratio with increase by $3 \%$.

II. Qualitative Performance: The graph in fig. 3 is TABLE III

SURVEY FROM STUDENTS ON PROJECT BASED LEARNING

\begin{tabular}{|c|c|c|}
\hline $\begin{array}{c}\text { Feedback from Students on } \\
\text { PBL }\end{array}$ & $\mathbf{2 0 1 8 - 1 9}$ & $\begin{array}{c}\mathbf{2 0 1 9}- \\
\mathbf{2 0}\end{array}$ \\
\hline $\begin{array}{c}\text { PBL helped me to obtain a basic } \\
\text { knowledge of Microcontrollers }\end{array}$ & 3.8 & 4.25 \\
\hline $\begin{array}{c}\text { PBL helped me to obtain a basic } \\
\text { knowledge of Communication } \\
\text { Protocols and Interfacing } \\
\text { Techniques }\end{array}$ & 3.8 & 4.3 \\
\hline $\begin{array}{c}\text { Knowledge acquired during PBL, } \\
\text { helped me in theory exams }\end{array}$ & 4.0 & 4.0 \\
\hline $\begin{array}{c}\text { Gained more consistency in work } \\
\text { throughout the semester due to } \\
\text { PBL }\end{array}$ & 3.3 & 4.1 \\
\hline $\begin{array}{c}\text { PBL improved my subject's } \\
\text { practical skills than does } \\
\text { traditional teaching }\end{array}$ & 4.1 & 4.1 \\
\hline $\begin{array}{c}\text { PBL increased my interest in } \\
\text { Microcontrollers Subject }\end{array}$ & 3.0 & 4.2 \\
\hline $\begin{array}{c}\text { The selected project will be } \\
\text { helpful to train me as an engineer }\end{array}$ & 2.9 & 4.2 \\
\hline
\end{tabular}

showing comparison between passing ratio of students in Microcontrollers course under University Exams from year 2018-19 (without PBL) and year 2019-20. $35.71 \%$ students received marks in range 51 to 60 and $19.05 \%$ students received marks above 60 (in Distinction) after PBL.
TABLE IV

SURVEY FROM STUDENTS ON PROJECT BASED LEARNING

\begin{tabular}{|c|c|c|}
\hline \begin{tabular}{|c|}
\hline SURVEY FROM STUDENTS ON PROJECT BASED LEARNING \\
\hline $\begin{array}{c}\text { I would recommend this PBL } \\
\text { approach for E\&TC students }\end{array}$
\end{tabular} & 3.9 & 4.3 \\
\hline $\begin{array}{c}\text { Work confidently into a group } \\
\text { To become a self-learner }\end{array}$ & 3.8 & 4.3 \\
\hline $\begin{array}{c}\text { Apply knowledge to solve real-time } \\
\text { problems }\end{array}$ & 4.1 & 4.3 \\
\hline $\begin{array}{c}\text { To understand report writing skills } \\
\text { To follow industry-oriented time } \\
\text { guidelines to accomplish the tasks }\end{array}$ & 3.5 & 4.3 \\
\hline
\end{tabular}

\section{Qualitative Performance of Students in Examination in (\%)}

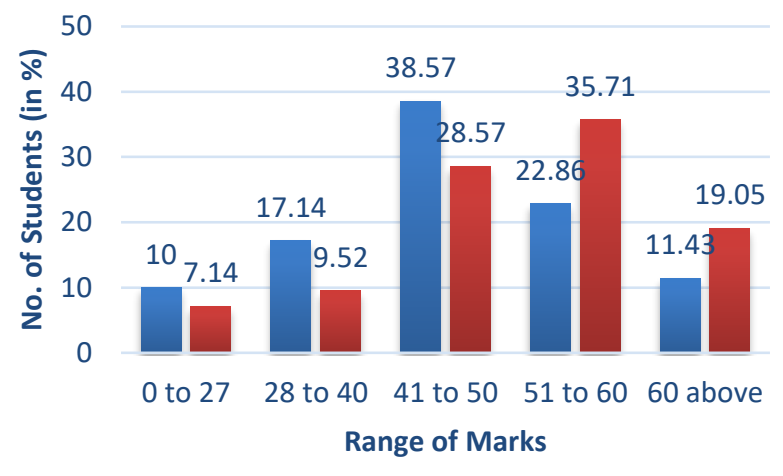

- of Year 2018-19 (without PBL) o of Year 2019-20 (with PBL)

Fig. 3. The graph is showing qualitative performance in results between last two years without PBL and with PBL students passing ratio.

In comparison with overall result of Microcontrollers course in the University exams, the result has been improved with $29 \%$ in Year 2019-20. The PBL has improved the student's performance in different ways. Following table II is showing remarks on University Examination results with PBL Approach.:

2) Students Aligned with Course Throughout the Semester: The project work is aligned with regular term-work. The practical experiments are also linked with PBL approach, so as to understand different IDE and Tools to work on various Microcontrollers and PCB designing Systems.

So, students continuously busy with PBL work for completion of task in stipulated time. So use of digital badges or Rubrics is essential [15] [16]. (Rubrics: - 1: Strongly Disagree, 2: Disagree, 3: Neutral, 4: Agree, 5: Strongly Agree). The feedback of students after PBL as shown in Table III, illustrates increase in joy of learning with PBL.

\section{3) Increased Student Interest:}

Satisfaction survey taken from students shows increased interest in Microcontrollers as shown in Table IV. They struggle more in interfacing and programming criterions from embedded systems design. Most of the students are reluctant for Microcontrollers subject. With above theme, the expert 
teachers evaluated the PBL reviews by means of a rubric benchmarks whose objectives are discussed here in Table V. This helped to motivate students for making their career in core electronics and circuit branches.

TABLE V

REVIEWS OF PBL ARE DEFINED BASED ON FOLLOWING POINTS

\section{Review Base \\ COMMENTS}

Design and

Feasibility analysis

The design of project and according to selection criteria, market survey, component availability and related modules are considered for further progress.

Project Simulations The steps in project distribute in all students as PCB design, model layout, Execution of project in Embedded ' $\mathrm{C}$ ' programming. So, at individual level these are verified with in-time workflow.

Number of The stages and modules implemented modules implemented from complete scope of project decides completion of objectives of PBL.

Members

contribution in project

Students learning skills are separate according to his capacity. So, even individual tasks are allotted, how he works as team to finish the project and also how he contributes his best as member are important grading points.

Report and Presentation Skills

Students are complete unaware of presentation skills. Thus, the suggestions received from faculty will be helpful for students while facing interviews

In comparison to IT Jobs, very limited vacancies are available in core electronics and embedded systems. So, the companies are looking for the students with extensive practical knowledge in core domains. The expertise reviews and presentation skills learned by students during PBL are motivating factors to achieve success in securing job in core electronics industries.

Hence, from placement point of view the Project Based Learning with practical approach proved role model to fulfill industry needs and demands by bridging gap by increasing Industry Institution Interactions.

\section{CONCLUSION}

In the under graduate studies, teaching the concepts in the course on Embedded Systems has been always challenge for the faculty. Inconsistency in practically learning the subject creates lack of confidence. Performance of the students is not up to mark as well as the joy of learning is also not observed in many students. The innovative experiments carried out with Project Based Learning (PBL) approach paved new practical way to make it interesting for the students
The study developed a method of self-learning to apply core electronics knowledge to increase student performance and keen interest in Microcontrollers and its applications. The feedback taken with surveys from students assured their skillsets in the CPU architecture, different protocols and interfacing with sensors to build their own project at individual level.

The new design method consists of eight-week PBL strategy to work in group of three students to solve real-world problems, such as home security using GSM and advanced protocols like Alexa with Node-MCU based Microcontroller.The enhancement in learning outcomes due to PBL approach is achieved with continuous progress evaluation in Rubrics. The average number of passing students in range of above 60 marks is improved by $8 \%$ in distinction class. The overall performance of the students is increased by $29 \%$ as compared to successive previous two years. Also, the feedback from the students shows satisfaction as well as joy of learning.

\section{REFERENCES}

[1] E. D. S. Zancul, T. T. Sousa-Zomer, and P. A. Cauchick-Miguel, "Project-based learning approach: improvements of an undergraduate course in new product development," Production, vol. 27, no. spe, 2017.

[2] A. Patton, Work That Matters The Teachers Guide to Project-based Learning. London: Paul Hamlyn Foundation, 2012.

[3] J. Macias-Guarasa, J. Montero, R. San-Segundo, A. Araujo and O. Nieto-Taladriz, "A Project-Based Learning Approach to Design Electronic Systems Curricula", IEEE Transactions on Education, vol. 49, no. 3, pp. 389-397, 2006.

[4] C. Chiang and H. Lee, "The Effect of Project-Based Learning on Learning Motivation and Problem-Solving Ability of Vocational High School Students", International Journal of Information and Education Technology, vol. 6, no. 9, pp. 709-712, 2016.

[5] Zhang, Z., Hansen, C. T., \& Andersen, M. A. E., Teaching Power Electronics with a Design-Oriented and Project-Based Learning Method at the Technical University of Denmark. IEEE Transactions on Education, 59(1), 32-38,2016.

[6] C. Chiang and H. Lee, "The Effect of Project-Based Learning on Learning Motivation and Problem-Solving Ability of Vocational High School Students", International Journal of Information and Education Technology, vol. 6, no. 9, pp. 709-712, 2016.

[7] F. Martinez-Rodrigo, L. Herrero-De Lucas, S. de Pablo and A. ReyBoue, "Using PBL to Improve Educational Outcomes and Student Satisfaction in the Teaching of DC/DC and DC/AC Converters", IEEE Transactions on Education, vol. 60, no. 3, pp. 229-237, 2017.

[8] E. Today and Desk, "Over $80 \%$ Indian engineers are unemployable, lack new-age technology skills: Report", India Today, 2020. [Online]. Available: https://www.indiatoday.in/education-today/news/story/over80-indian-engineers-are-unemployable-lack-new-age-technology-skillsreport-1483222-2019-03-21. [Accessed: 14- May- 2020]

[9] .M. Grant, "Learning, Beliefs, and Products: Students' Perspectives with Project-based Learning", Interdisciplinary Journal of Problem-Based Learning, vol. 5, no. 2, 2011.

[10] M. Zapater, P. Malagon, J. Goyeneche and J. Moya, "Project-Based Learning and Agile Methodologies in Electronic Courses: Effect of Student Population and Open Issues", Electronics ETF, vol. 17, no. 2, 2013.

[11] "94\% of engineering graduates are not fit for hiring, says this IT stalwart", The Economic Times, 2020. [Online]. Available: https://economictimes.indiatimes.com/jobs/only-6-of-those-passing-outof-indias-engineering-colleges-are-fit-for-ajob/articleshow/64446292.cms?from=mdr. [Accessed: 14- May- 2020].

[12] "Gold Standard PBL: Essential Project Design Elements", PBLWorks, 2020. [Online]. Available: https://www.pblworks.org/blog/goldstandard-pbl-essential-project-design-elements. [Accessed: 14- May2020]. 
[13] H. V. Mekali and P. Patil, "Project based learning for a course on advanced microcontroller: Experiment and results: A case study from BMS College of Engineering, Bangalore, India," 2014 IEEE International Conference on MOOC, Innovation and Technology in Education (MITE), Patiala, 2014, pp. 128-131

[14] A. Stojcevski and D. Fitrio, "Project Based Learning Curriculum in Microelectronics Engineering," 2008 14th IEEE International Conference on Parallel and Distributed Systems, Melbourne, VIC, 2008, pp. 773-777

[15] J. Liao, S. Hooper and M. Wang, "Incorporating Digital Badges and Ontology into Project-Based Learning," 2014 IEEE 14th International Conference on Advanced Learning Technologies, Athens, 2014, pp. $403-$ 405

[16] S. McLoone, B. Lawlor and A. Meehan, "On Project Oriented Problem Based Learning (POPBL) for a first year engineering circuits project," 25th IET Irish Signals \& Systems Conference 2014 and 2014 ChinaIreland International Conference on Information and Communications Technologies (ISSC 2014/CIICT 2014), Limerick, 2014, pp. 386-391

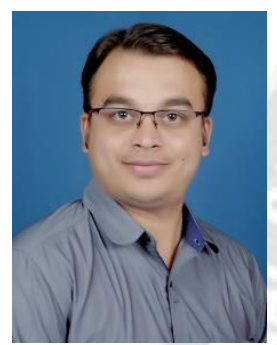

Harshad N. Lokhande (M'16) received the B.E. degree in Electronics and Telecommunication Engineering from Shivaji University, Kolhapur, India, in 2006 and the M.E. degree in Electronics and Telecommunication Engineering from Savitribai Phule Pune University, Pune, India, in 2017. Currently pursuing Ph.D. in Image Processing from Savitribai Phule Pune University, Pune.

From 2007 to 2009, he was a Control Engineer with the Black and Veatch India Pvt. Ltd, Pune, India. His work area includes the development of PLC and SCADA programs, GE's D20 Remote Terminal Units for substation automation projects. Since 2014, he has been working as Assistant Professor in NBN Sinhgad School of Engineering, Pune, India. Total Experience of 9 years (Teaching \& Industrial). His research interests are microcontrollers, embedded systems, image processing and deep learning.

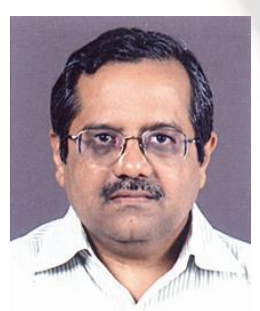

Dr. Shriram D. Markande (M'16) received the M.E. degree in Electrical Engineering from Pune University, India in 1999 and Ph.D. in Electronics Engineering from Bharati Vidyapeeth University, Pune, India, in 2010.

Since 2006 he has been working as Principal \& Professor in Electronics and Telecommunication Engineering with Sinhgad Institutes, Pune, India. He has total experience of 35 years with one book and 30 plus papers. His research interests include Wireless communication. $\mathrm{He}$ is Fellow of Institution of Electronics \& Telecommunication Engineers. 